\title{
Legal rehabilitation of health professionals in New Zealand
}

Kate Diesfeld, Rosemary Godbold

\begin{abstract}
Aims: A common understanding of 'rehabilitation' is the restoration of physical or mental
functioning. However, sometimes the concept is applied by professional disciplinary bodies to restore poorly performing health practitioners to their former level of professional functioning. This article aims to research what 'rehabilitation' means, in the context of New Zealand law.
\end{abstract}

Methods: A range of cases were considered to assess what rehabilitation consists of, and when disciplinary boards choose to use it. Where discrepancies between decisions gave rise to questions, further analysis was carried out.

Findings: It can be seen that the New Zealand's disciplinary decisions do not appear consistent, particularly differing by profession. Nevertheless, a clearer approach is beginning to emerge, one which should become more so in the future.

Conclusions: Analysis of New Zealand's disciplinary decisions may contribute to the rich international research on professional regulation.

Key words: $\square$ professional competence $\square$ professional discipline $\square$ malpractice $\square$ negligence - regulation of health professionals rehabilitation for misconduct

Submitted 10 December 2009, sent back for revisions 11 January 2010; accepted for publication following double-blind peer review 22 February 2010

$\mathrm{H}$ ow does the concept of rehabilitation feature in law? A common understanding of 'rehabilitation' is the restoration of physical or mental functioning. However, sometimes the concept is applied by professional disciplinary bodies to restore poorly performing health practitioners to their former level of professional functioning. This article examines how New Zealand law incorporates rehabilitation when disciplining registered health professionals.

Professional regulation has been the subject of substantial international scholarship, including the application of therapeutic jurisprudence (Freckelton and Flynn, 2004; Freckleton, 2007). Also, a therapeutic approach is aligned with the restorative justice model proposed in a study of the Australian Council for Safety and Quality in Health Care by Braithwaite et al (2005), as referenced by Freckelton (2005b).

\section{METHODS}

Decisions of New Zealand's Health Practitioners Disciplinary Tribunal (the Tribunal) illustrate that rehabilitation is often, but not always, relevant to penalties. However, neither the governing legislation nor the Tribunal decisions explicitly define what rehabilitation is, or should involve. Therefore, case analysis is used to derive an understanding of rehabilitation in this context. Based on Tribunal decisions, this analysis raises a range of questions: How consistently does the Tribunal apply rehabilitation? What principles does the Tribunal apply? Who is worthy of rehabilitation? What types of misconduct and conditions qualify for rehabilitation?

This inquiry will interest health practitioners (including those within the field of rehabilitation) and researchers who study the functioning of review bodies. The analysis may contribute to comparative international research, because other countries face similar issues of parity in the discipline of those who transgress the boundaries of acceptable practice. Practitioners (and their legal advocates), registration bodies and tribunal members have an interest in understanding how decisions are made. Likewise, health consumers may benefit from research on disciplinary proceedings, because the primary purpose of the Health Practitioners Competence Assurance Act 2003 (the Act) 'is to protect the health and safety of members of the public' (Section 3(1)).

Uniform decision-making is critical because the purpose of the Act (and corresponding aim of the Tribunal) is 'a consistent accountability regime for all health professionals' according to 
Section 3(2)(a). In scrutinizing the use of principles such as rehabilitation, we expand our ability to constructively critique decision-making by disciplinary bodies in New Zealand and abroad.

\section{FINDINGS}

\section{Comparison of penalties}

The first case comparison indicates variations in how the Tribunal administers rehabilitation and involves misuse of medication by a doctor and by a nurse:

Dr A was disciplined for inappropriate prescribing and misuse of drugs. Due to his history of drug addiction, he was under a medical monitoring programme for previous misconduct (Med07/80P). Despite this, he performed an estimated 49 unnecessary procedures (including liver biopsy) to access pain medication between mid-2005 and February 2006. To self-administer pethidine prescribed for patients, he substituted saline. Although the Tribunal suspended Dr A from practice for one year, he was not prosecuted under criminal law.

While the Tribunal viewed this as a serious breach of Dr A's obligations, the rehabilitative penalty noted that he took preventive measures to understand his addiction. Rehabilitation featured largely in the penalty. The Tribunal grappled to: 'reconcile the need to protect the public and maintain professional standards against its real desire to rehabilitate the doctor insofar as the Tribunal is able and to allow him to be a member of the... medical community.' (Med07/80P: 33)

Consequently, the panel offered the doctor a final opportunity for rehabilitation and did not cancel his registration.

In contrast, a nurse with fewer and less serious incidents received a very different penalty. In 2006, $\mathrm{Mr} \mathrm{H}$ stole vials of morphine, pethidine and fentanyl from a locked drug safe, removed some for his own use and returned the vials to disguise his theft (Nur07/67P). The Tribunal held that this behaviour posed a potential safety risk by dangerously reducing the dose of medication administered to patients. Adversely reflecting on Mr H's fitness to practice, the theft constituted illegal, immoral, unethical and dishonest conduct. In addition to de-registration, he was ordered to pay a contribution to the costs of the disciplinary proceedings. Unlike Dr A, this nurse was criminally prosecuted under the Misuse of Drugs Act 1975 (as were 5 nurses for broadly similar misconduct (Nur06/38P, Nur07/51P, Nur07/52P, Nur07/68P, Nur07/69P)). Importantly, the Tribunal did not report whether it contemplated rehabilitation for $\mathrm{Mr} \mathrm{H}$.
The marked distinction in these penalties inspired a further exploration of the Tribunal's perspective on rehabilitation.

\section{Overview of New Zealand's disciplinary system}

New Zealand's unusual medico-legal system incorporates a no-fault accident compensation scheme. In 1976, the adoption of compensation for accident and injury generally barred personal injury litigation, including medical malpractice (Manning, 2006). The current legislation is the Injury Prevention, Rehabilitation, and Compensation Act 2001. For a discussion of injured consumers' dissatisfaction with nonmonetary remedies see Bismark et al (2006). Consequently, the disciplinary regime has particular significance for public safety, the maintenance of professional standards and punishment of practitioners in New Zealand (Diesfeld and Godbold, 2009).

In the absence of medical malpractice litigation, gaps opened in the protection of patients. Some practitioners were not sufficiently held accountable for misconduct, as illuminated by the Cartwright Inquiry, commissioned by the Ministry of Health (Cartwright, 1988). In response, the Health and Disability Commissioner Act 1994 established the foundation for 10 patients' rights (Health and Disability Commissioner (Code of Health and Disability Services Consumers' Rights) Regulations 1996). The Code was not designed to replicate a litigious, adversarial environment; the Commissioner has promoted an ethos of learning, not lynching (Paterson, 2008).

Another strand of patient safety involves the regulation of registered health practitioners. Historically, New Zealand practitioners were disciplined by their own professional bodies. However, the Cull Report (Cull, 2001) identified significant shortcomings in New Zealand's system of selfregulation by health practitioners. Consequently, the regulatory arrangements were reformed in the new Act in 2003.

New Zealand's disciplinary system is pan-professional. The Health Practitioners Competence Assurance Act 2003 (the Act) states that it establishes a consistent regulatory system for health practitioners to protect the public health and safety. Currently, 19 occupational groups are listed on the Health Practitioners Disciplinary Tribunal website and the most recent to apply for registration is psychotherapy.

Of international interest, the resulting Tribunal hears cases from across the spectrum of registered health professions. The composition of the panel includes three members of the relevant profession, a 
legal chair and a lay member. When there is a finding of guilt, a penalty is issued. Variations in penalties across the cases raise fascinating questions (Diesfeld, 2007; Godbold, 2008; Diesfeld, 2009; Diesfeld and Godbold, 2009), particularly in relation to rehabilitation.

\section{Grounds for discipline}

The Tribunal hears disciplinary cases involving a range of matters. Pursuant to section 100(a), 'practitioners may be found guilty of misconduct because of any act or omission that, in the judgment of the Tribunal, amounts to malpractice or negligence in relation to the scope of practice in respect of which the practitioner was registered at the time'. Of relevance for this analysis, another ground for discipline is misconduct that has brought, or is likely to bring, discredit to the profession. Additional bases for discipline under Section 100 are:

Convictions of an offence that reflects adversely on the person's fitness to practice

Practising without a certificate

Practising outside the designated scope of practice

Failure to observe conditions placed on practice

Or breach of a Tribunal order.

Malpractice is not defined in the Act. Manning concludes that while 'malpractice' is an imprecise term, it is interpreted in New Zealand as a 'broader concept than negligence, while being capable of encompassing neglect' (Manning, 2006: 630). She lists examples of malpractice: 'trespassory conduct during care of a patient in relation to consent; breaches of patient confidence and fiduciary duties'; and misconduct of sufficient gravity to qualify for discipline 'such as assault of a patient; swearing at or threatening a patient; and deliberate failure to obey an instruction or sexual misconduct' (Manning, 2006: 631).

In determining whether sanction is warranted, the panel applies 'an objective test that is based on the reasonable expectations of colleagues balanced by those of the non-professional member and the legal Chair.' (Manning, 2006: 621). The actual personal circumstances of the practitioner, such as 'knowledge and experience', are relevant to the penalty (Manning, 2006: 622). The composition of the panel changes, dependent on the occupation of the health practitioner. Despite this, the Tribunal aims for consistent discipline across the occupational groups (Patel $v$ The Dentists Disciplinary Tribunal HC AK AP77/02, 8 October 2002; Section 3 (2)(a)). One challenge for the Tribunal is consistency across all professions, and one barometer of its success may be demonstrated in how it administers rehabilitation.

When there is a finding of guilt, the Tribunal considers a spectrum of potential penalties. The potential penalties, given in Section 101, are:

Cancellation of registration

Suspension (not to exceed 3 years)

Conditions as to employment

Supervision or other factors (after commencing practice for a period to not exceed 3 years)

Censure

Fine not to exceed $\$ 30,000$

Costs and expenses (of the inquiry, the prosecution by the Director of Proceedings or professional conduct committee, or the Tribunal hearing).

Although the Act is silent about the relevant factors for issuing a penalty, the Tribunal decisions offer some guidance on the 'sentencing principles' that apply.

\section{Rehabilitation as a sentencing principle}

Typically, the decisions report that the penalty must fulfil the following functions:

Protecting the public

Maintenance of professional standards

Punishment

Rehabilitation (for example Med 07/80P).

On 22 November 2009, 123 cases were reported across the 19 professions on the Health Practitioners Disciplinary Tribunal website. The finding was not guilty in nine cases. Four cases were withdrawn and one was stayed/struck out. While public safety was relevant in deciding the penalty in all 109 cases with a finding of guilt, rehabilitation was not.

Occasionally general and public deterrence were referenced (e.g. Nur09/116P and Phar07/ $66 D)$. For a decision referring to 'specific and general deterrence', see Med06/44P, citing Professional Conduct Committee v Martin, Gendall, J, 27 February 2007 CIV-2006-485-1461, Wellington Registry. For discussion of the role of disciplinary penalties upon deterrence, see Freckelton (2005b).

One means to test consistency is case analysis of penalties. Case analysis must also acknowledge that tribunal decision-making is admittedly a complex social and legal process (Diesfeld and McKenna, 2006; Diesfeld and Sjostrom, 2007). The deliberative process is not fully portrayed in the written decision. However, the written document is the sole method of discerning how decisions are made and therefore the basis of case analysis. Rehabilitation is the focus of this analysis because the ability to continue or resume practice is of utmost concern to most practitioners. 


\section{Is rehabilitation consistently applied as a sentencing principle?}

Case analysis indicates that the Tribunal selectively applies rehabilitation as an element of sentencing. For example, rehabilitation was referenced in the Tribunal's first (Med 04/01D) and in its most recent (Nur09/124P) cases. But many cases do not state that rehabilitation is a relevant sentencing factor (See for example Med04/03P and Den05/05P). The significance of this is illuminated by examination of a pattern across decisions within one occupational group.

Of 10 pharmacist cases, three did not list rehabilitation as a 'sentencing principle' (Phar07/75P, Phar07/74P, Phar07/78P). Thus, the written decisions suggest that the Tribunal did not consider rehabilitation in all cases. Consistency is a core feature of a just system and has a significant impact for practitioners who are subject to regulatory intrusion, yet it does not appear to exist here.

Further, since an explicit definition of rehabilitation is not provided in the Act or in the decisions, consistency does not necessarily exist even where it is mentioned as a 'sentencing principle'. One method by which an understanding of the concepts being applied can be reached - in this case rehabilitation - is through the application of precedent.

Precedent is a legal case establishing a principle or rule that a judicial body applies when deciding subsequent cases with similar issues or facts. That is, a case that is subsequently cited provides the authoritative source of a principle. Precedent is an important dimension of the common law process for ensuring consistent decisionmaking and applies to tribunal decision-making.

\section{Is precedent consistently applied?}

Does the New Zealand Tribunal consistently apply precedent? In the seven most recent nurses' cases, five mentioned rehabilitation (Nur09/ 118P; Nur09/117; Nur09/116; Nur09/122; and Nur09/115). Of those, only four referred to case law as precedent for decisions regarding whether to offer rehabilitation (The following cases cited $B v B$ CA213/044 May 2005, and $J v$ Director of Proceedings 17/10/06, Baragwanath J, HC Auckland CIV-2006-404-2188 in relation to rehabilitation: Nur09/118P; Nur09/117; Nur09/116; Nur09/115D). Thus, it appears that precedent is not consistently applied.

One example illuminates the broader impact of this phenomena. An important case relating to rehabilitation was decided in the High Court in 2006 ( $J v$ Director of Proceedings). A psychiatrist (Dr J) pled guilty to charges before the Tribunal, for failure to properly document his consultations, observations and decision-making processes. He also failed to manage and control drugs that the patient was receiving. The psychiatrist appealed the Tribunal decision to the High Court on all penalties except censure. In this case, Justice Gendall explained factors that are relevant to rehabilitation:

“[A]... practitioner, and particularly one

with a good record, who has proved

ready, willing and able to undertake rehabilitation is concurrently displaying the remorse and evidence of rehabilitation that are germane to the imposition of any penalty.' (Paragraph 52)

This case identifies factors that the Tribunal should consider when contemplating rehabilitation. However, the Tribunal only cited the above case in four of the seven most recent decisions relating to nurses. Based on the written decisions, it appears that the Tribunal did not consider rehabilitation for the remaining three nurses. Perhaps these nurses, and other practitioners, are disadvantaged because they do not receive the full benefit of remediation. Given this anomaly, several analytic frameworks were applied in an attempt to understand the Tribunal's reasoning regarding rehabilitation.

\section{Who is worthy?}

On occasion, the Tribunal reported its role is to rehabilitate 'worthy' health professionals (See for example Med 07/70P and Dr. A (Med07/ $80 P)$ ). How does it decide who is worthy? Dr A's case reveals some relevant factors:

'The Tribunal must consider rehabilitation of the practitioner if it is worthy of this course of action... and [Dr A's] job as a general practitioner was going extremely well... [He] had a rare skill set of scientific knowledge, understanding secondary care and an ability to communicate with and lead a diverse team." Med07/80P: 24 After much deliberation, the Tribunal held that Dr A was 'worthy of one final chance of rehabilitation' (Med 07/80P: 33).

Sometimes the Tribunal measures practitioners' worthiness based upon his or her contribution to the community. Like Dr A, Dr K had a history of drug and alcohol addiction (Med $06 / 29 P)$. He was disciplined numerous times for prescribing irregularities, obtaining opiates for his own use and drink driving. Yet the Tribunal aimed to rehabilitate this doctor 'if at all possible' based on evidence that he was dedicated and provided a very valuable service to a needy population in a socially deprived community.

Similarly, the Tribunal deemed a pharmacist worthy of rehabilitation after inappropriate possession of medication (Phar05/10P). She was found guilty of dispensing drugs (includ- 
ing Viagra and Xenical) without prescriptions to customers from England, Italy and the United States. Yet the penalty enabled her to practice if she wished, because the Tribunal was persuaded that she was conscientious and a 'well respected member of the community who has made many worthwhile contributions to society' (Phar05/ 10P: 21). While this pharmacist received a relatively lenient penalty of 3 months suspension (combined with being fined, censured and required to pay $35 \%$ costs), another nurse ( $\mathrm{Mr} \mathrm{F}$ ) who misappropriated and inappropriately administered prescription drugs was not considered deserving of rehabilitation (Nur05/26P).

What could account for this pattern? Perhaps some professions are viewed as more deserving of investment than others (e.g. medicine and pharmacy). Perhaps the Tribunal is aware that some professionals may be relatively more difficult and costly to replace. Finally, there may be an unconscious bias towards offering lenient sentences to members of higher-status professions.

The case analysis indicates that the Tribunal does not always consider whether the practitioner is deserving of rehabilitation. Consequently, the threshold of worthiness is blurred. Given that substance abuse featured in the majority of the above cases, it was the foundation for the next analysis.

\section{Are addictions and mental illness the rationale for rehabilitation?}

A traditional medical definition of rehabilitation means to restore a person's functioning capacity. Laypeople may view rehabilitation as a response to illness, disability or addiction issues. Indeed, practitioners' personal health may impair their ability to practice effectively and safely, as noted from the above cases and international scholarship (Reid, 2005; Freckelton and Molloy, 2008). Therefore, the next analysis examined whether the Tribunal applied rehabilitation primarily to psychiatrically unwell and substance dependent practitioners. For a discussion of remedial programmes for impaired health practitioners in Australia, see Freckelton and Molloy (2008).

In relation to drug-dependence, the review body developed a rehabilitative response for two doctors, Dr A (Med07/80P) and Dr K (Med06/ $29 P$ ), but not for Ms A, a nurse who misappropriated drugs for her own use (Nur 07/69P).

Regarding mental illness, the Tribunal took account of one nurse's major depressive disorder in designing a lenient, restorative response (Nur05/16D). The Tribunal noted that Nurse E voluntarily pursued relevant advanced studies prior to the hearing. Of note, the Tribunal authorized permanent name suppression because disclosure would 'militate against the ability to rehabilitate the practitioner', citing $B v B$.

Mental illness and addiction are not the sole grounds for this type of penalty. Problematic gambling was relevant to rehabilitation of a nurse who sexually assaulted his former partner. Also, a doctor who produced false or misleading documents was offered a restorative penalty (Med08/ $96 P)$. He was required to pay for monitoring by the Medical Council and complete an accreditation course on auditing. From this, it seems that the Tribunal does not confine rehabilitation to the unwell or addicted practitioners, although this has not been clearly articulated in decisions. Given the lack of clarity surrounding rehabilitation, the next analysis examines whether rehabilitation is linked to the type of offending behaviour.

\section{What types of misconduct are awarded a rehabilitative penalty?}

Recent Tribunal decisions reference a continuum of misconduct justifying rehabilitation, from the least to the most serious. The application of rehabilitation across this continuum is illustrated by sexual misconduct cases, with a marked evolution in the Tribunal's response to sexually inappropriate relations by nurses. For discussion of the variation in penalties for clinical errors and for character-related misconduct, see Godbold and Diesfeld (2006). Reid (2005) has categorized professional misconduct as unethical, reckless, criminal and wilful.

In 2006, the Tribunal de-registered a nurse and she was required to wait 2 years to re-apply (Nur05/25P). Although she had not engaged in a physical sexual relationship, she became intimately involved with her patient (a prisoner) and some of her letters were very sexually explicit. Although the Tribunal noted that this constituted the low end of the spectrum of offending, it applied the most severe penalty and offered no rehabilitation.

Two years later, a shift in its stance can be detected from a case where the Tribunal issued a penalty to restore a nurse's ability to practice after sexual misconduct. Although $\mathrm{Mr} \mathrm{M}$ was deregistered, the penalty also incorporated: a psychiatric assessment; a medical assessment for drug and alcohol dependence; and completion of a post-graduate course in medical ethics and professional boundaries (Nur08/104D). He also had a history of drug and amphetamine abuse.

Seven months later, the Tribunal explicitly addressed rehabilitation for sexual misbehaviour by a nurse:

'Rehabilitation is seen as less relevant in sexual offending. In these cases, 
public safety is the most important consideration.' Nur08/112D: 30

Nevertheless, the Tribunal addressed the nurse's rehabilitative need for further training, supervision and health assessment, enabling the nurse to resume practice. Therefore, a range of conduct qualifies for rehabilitation, from drug misuse to recent decisions involving sexual misconduct. This leads to an analysis of the Tribunal's balancing process.

\section{How is public risk relevant to rehabilitation?}

The core function of the legislation is public protection. Therefore, this analysis inquires whether errant practitioners who posed a high risk to the community were less likely to be offered rehabilitation by the Tribunal. The starting point is a comparison of two physiotherapy decisions.

Both cases concerned accident compensation fraud. In the less serious case, the physiotherapist dishonestly claimed $\$ 4,432$ under the accident compensation system (Phys06/43P). Although he was suspended from practice for six months, the Tribunal considered rehabilitation. On re-application for registration, he was required to undergo supervision and monitoring for one year, with emphasis on improving the quality and accuracy of his accounting practice, and to ensure his practice was in accordance with ethical principles.

In the second, more egregious case the physiotherapist fraudulently obtained $\$ 300,485$ (Phys06/45P). For this much graver offence, rehabilitation was not listed as a sentencing principle. The physiotherapist received the harsher penalty of de-registration, censure and payment of $50 \%$ of the costs. Based on this preliminary comparison, it appears that more serious offences are less likely to receive rehabilitative penalties.

However, penalties for other professional groups defy this pattern. When a nurse (Ms J) committed the very serious act of medicating dementia patients without prescriptions, the Tribunal reported that her misconduct 'undermined the trust and responsibilities reposed in nurses and was potentially dangerous' (Nur05/ 20P: 15 - emphasis added). Yet the Tribunal accepted that Ms J was unable to cope with the stresses in her life and challenges of caring for dementia patients. Consequently, the Tribunal 'construct[ed] a penalty to enable Ms J to continue to practise as a nurse if she wishes' (Nur05/ 20P: 16). The penalty included $\$ 10,000$ towards costs. Although Ms J could be viewed as a high risk to future patients, the Tribunal provided a strategy for her to resume practice. Ms. J was required to undergo 2 years supervision a com- petence assessment by the Nursing Council to resume practice.

Additional cases provide further contrast. As analysed above, Dr. A's long-established addiction posed a significant risk to the public (as demonstrated by 49 unnecessary and invasive procedures); he had rehabilitative options (Med07/80P). Nurse H's drug-related misconduct posed a lesser risk; he was not granted rehabilitation $($ Nur07/67P).

Public protection is a complex and subtle factor for disciplinary bodies to address (Freckelton, 2005b) and the Tribunal acknowledged the challenges of this delicate process, as noted in $\mathrm{Dr}$ A's decision (Med07/80P: 33). Although Dr A administered unnecessary, significantly invasive procedures, 'after much debate' the Tribunal considered that he was 'worthy of one final chance of rehabilitation' (Med07/80P: 33). Likewise, in disciplining Dr K, the panel 'weighed uppermost the need for the Tribunal to protect the public, maintain professional standards and to try and rehabilitate $\mathrm{Dr} \mathrm{K}$ if at all possible' (Med06/29P: 13).

Despite this, it is difficult to reconcile the Tribunal's claims about the uniform balancing of risk and rehabilitation with other decisions. For example, a 62 year old nurse ( $\mathrm{Mr} \mathrm{W}$ ) was found guilty of malpractice for taking provisions from the hospital supplies for his own use (Nur08/ $110 P)$. Mr W was suspected of ongoing theft of ward provisions and on one particular occasion was found to have taken four bananas, a packet of disposable spoons, two litres of fresh milk and a container of yoghurt. After the police and human resources were alerted, he was dismissed from his employment. While rehabilitation was noted as a function of disciplinary proceedings, the Tribunal suspended Mr W for six months to protect the public and maintain professional standards. In comparison with other decisions, this penalty could be perceived as disproportionate to the public risk posed by that $\mathrm{MrW}$.

\section{DISCUSSION}

This analysis of a small selection of decisions by a relatively new review body has limitations for generalizability. Unfortunately, the written decisions do not report the complete spectrum of relevant factors and the full reasoning that occurred during panel deliberations (and see Diesfeld and McKenna, 2006; Diesfeld and Sjostrom, 2007). However, future cases from across the diverse professions will provide a larger sample and hopefully greater clarity regarding the legal definition of rehabilitation. 
Within the existing decisions, the Tribunal acknowledged that it struggles with the concept of rehabilitation. The panel's sporadic application of precedent bears this out, and the definition of rehabilitation remains obscure. Sometimes worthiness is explicitly evaluated by the panel. Apparently public risk is one of a range of issues relevant to a rehabilitative penalty. Based on a comparison of broadly similar misconduct, it appears that some professions may be granted more restorative (and lenient) penalties than others. In some respects, it is clear that the Tribunal has not yet fully realised the Act's core function of establishing a consistent regime across professions, if rehabilitation is the criteria.

Nevertheless, it appears that the Tribunal is beginning to articulate the circumstances under which rehabilitation is appropriate. The disciplinary body seems to be extending rehabilitation to a range of behaviour, from misuse of drugs to fraud and sexual misconduct. The restorative approach is not limited to people who were mentally unwell or substance dependent at the time of the problematic incidents. In the absence of a concrete definition, the decisions provide some insight into how the Tribunal interprets and applies the concept of rehabilitation.

\section{CONCLUSIONS}

Further clarification in future decisions is expected based on a recent decision. In August 2009, the Tribunal offered rehabilitation to a nurse based on precedent and called for greater consistency. In Nur09/116P: 9, the Tribunal cited relevent principles from two court cases. First, the Tribunal cannot ignore the rehabilitation of practitioners. Secondly, while public confidence in the professions should outweigh the practitioners interests, that is not absolute: 'the existence of the public interest in not ending the career of a competent doctor will play a part'.

Regarding consistency, the Tribunal cited the following authority:

\section{KEY POINTS}

Disciplinary bodies may have wide discretion in issuing penalties for misconduct.

- Rehabilitation may be a relevant consideration in determining a professional's ultimate penalty.

- To restore practitioners to practice, disciplinary bodies may consider rehabilitation for a range of misconduct, from misuse of drugs, to fraud and sexual transgressions.

- Consistent discipline within and across professions is a fertile foundation for international comparisons.
'I respectfully adopt the observations of the Privy Council and would add that it is incumbent on the Tribunal to consider carefully the alternatives available to it short of removal, and to explain why the lesser options have not been adopted... [W] hile absolute consistency is something of a pipe dream, and cases are necessarily fact dependent, some regard must be had to maintaining reasonable consistency with other cases. That is necessary to maintain the credibility of the Tribunal as well as the confidence of the profession and the public at large.'

Patel v The Dentists Disciplinary Tribunal.

Although this case was available and relevant, it was not consistently cited in all decisions of the new tribunal after its establishment under the 2003 Act.

Accordingly, the New Zealand Tribunal will be held to a high standard of accountability when they do, or do not, address the rehabilitation of each health practitioner.

Hopefully this decision will create a more coherent approach to discipline. Consistent and proactive strategies may assist more practitioners to resume practice in appropriate circumstances.

Perhaps New Zealand will contemplate Australia's strategy away from the 'conduct pathway' into the 'health pathway' and the 'performance pathway' (Freckelton, 2005b: 153). The Australian strategy encourages practitioners to address health impairments, such as substance dependency and mental illness, and to address deficits in their knowledge and technique (Freckelton, 2005b).

In turn, analysis of New Zealand's future disciplinary decisions may contribute to the rich international research on professional regulation (Freckelton, 2005a; b; and 2008; Reid, 2005; MacLeod and McSherry, 2007; Davies, 2007). International comparisons may ensure that rehabilitation is considered for the worthy in a transparent fashion, across the professions and spectrum of misconduct cases, from theft of food to unnecessary liver biopsies. IJTR

Conflict of interest: none

Acknowledgements: The IJTR reviewers' recommendations and perspectives of AUT University students are gratefully acknowledged.

Bismark M, Dauer E, Paterson P, Studdert D (2006) Accountability sought by patients following adverse events from medical care: The New Zealand experience. CMAJ 175(8): 889-94

Braithwaite J, Healy J, Dwan K (2005) The Governance of Health Safety and Quality. Commonwealth of Australia, Canberra

Cartwright S (1988) Report of the Committee of Inquiry into Allegations Concerning the Treatment of Cervical Cancer at National Women's Hospital. Government Printing Office, Wellington

Cull H (2001) Review of Processes Concerning Adverse 
Medical Events. Ministry of Health, Wellington

Davies M (2007) Medical Self-Regulation: Crisis and Change. Ashgate, Aldershot

Diesfeld K, Godbold G (2009) Disciplinary developments in New Zealand. International Journal of Therapy and Rehabilitation 16(10): 557-63

Diesfeld K (2009) Benefits and critique of New Zealand's Health Practitioners Competence Assurance Act 2003. International Journal of Therapy and Rehabilitation 16(1): $55-6$

Diesfeld K (2007) Lessons from the Health Practitioner Disciplinary Tribunal. New Zealand Doctor 6 June: 8-9

Diesfeld K, Sjostrom S (2007) Interpretive flexibility: Why doesn't insight incite controversy in mental health law? Behav Sci Law 25(1): 85-101

Diesfeld K, McKenna B (2006) The therapeutic intent of the New Zealand Mental Health Review Tribunal. Psychiatry Psychology and Law 13(1): 100-10

Freckelton I, Flynn J (2004) Paths toward reclamation: Therapeutic jurisprudence and the regulation of medical practitioners. J Law Med 12(1): 91-102

Freckelton I ed (2005a) Regulating health practitioners. Law in Context 23(2): 1-254

Freckelton I (2005b) The margins of professional regulation: Disjunctions, dilemmas and deterrence. Law in Context 23(2): $148-170$

Freckelton I (2007) Disciplinary investigations and hearings: A therapeutic jurisprudence perspective. In Australasia Institute of Judicial Administration, Transforming Legal Processes in Court and Beyond. A Collection of Papers from the 3rd International Therapeutic Jurisprudence Conference 2006 Perth. http://tinyurl.com/yho93rq (accessed 18 March 2010)

Freckelton I, Molloy P (2008) The health of health practitioners: Remedial programs, regulation and the spectre of the law. J Law Med 15(3): 366-82

Godbold R, Diesfeld K (2006) Scrutinising the conduct of health professionals. Nur $N Z$ 12(10): 22-3

Godbold R (2008) Physiotherapy and the new disciplinary process. New Zealand Journal of Physiotherapy 36(3): 131-7

MacLeod A, McSherry B (2007) Regulating mental healthcare practitioners: Towards a standardised and workable framework. Psychiatry, Psychology and Law 14(1): 45-55

Manning J (2006) Treatment injury and medical misadventure In: Skegg PDG, Paterson R eds. Medical Law in New Zealand. Thomson Brookers, Wellington Ch. 24
Paterson R (2008) Inquiries into health care: learning or lynching? (Nordmeyer Lecture). University of Otago, Dunedin

Reid A (2005) To discipline or not to discipline? Managing poorly performing doctors. Law in Context 23(2): 91-112

\section{Information about the Health Practitioners Disciplinary} Tribunal: About the Health Practitioners Disciplinary Tribunal. Online. http://tinyurl.com/kq24qh (accessed 17 March 2010). Also www.hdpt.org.nz

\section{Legislation: available at www.nzlii.org.nz}

Health and Disability Commissioner Act 1994

Health and Disability Commissioner (Code of Health and Disability Services Consumers' Rights) Regulations 1996, Schedule.

Injury Prevention Rehabilitation and Compensation Act 2001

Misuse of Drugs Act 1975

Health Practitioners Competence Assurance Act 2003

\section{Cases:}

$A$ v PCC, Keane J, VIV-2008-404-2927 5 September 2008

$B$ v B CA213/044 May 2005

Giele the Medical Council [2005] EWHC 2143

$J v$ Director of Proceedings 17/10/06, Baragwanath J, HC Auckland CIV-2006-404-2188

Patel $v$ The Dentists Disciplinary Tribunal HC AK AP77/02, 8 October 2002

Professional Conduct Committee v Martin, Gendall, J, 27 February 2007 CIV-2006-485-1461

The decisions of the Health Practitioners Disciplinary Tribunal are located at www.hpdt.org.nz and can be searched for using: Den05/05P; Med 04/01D; Med04/03P; Med06/44P; Med 06/29P; Med 07/70P; Med07/80P; Med08/96P; Nur05/16D; Nur05/20P. Nur05/25P; Nur05/26P; Nur06) 38P; Nur07/51P; Nur07/52P; Nur07/67P; Nur07/68P; Nur07/69P; Nur08/104D; Nur08/110P; Nur08/112D; Nur09/115; Nur09/116P; Nur09/117; Nur09/118P; Nur09/ 124P; Nur09/122; Phar07/66D; Phar07/74P; Phar07/75P; Phar07/78P; Phar05/10P; Phys06/43P

\section{COMMENTARIES}

Health professionals hold a unique position in society, as they have direct contact with the public, for the diagnosis, care and treatment of patients. Moreover, the power relationship between health professionals and the public tends to be unbalanced, in that health professionals hold specialized knowledge and skills which are likely to influence patients' health and wellbeing. As such, public safety is of utmost concern.

Trainee health professionals develop knowledge, skills and competencies not only with respect to the safe and effective delivery of care, but also in the area of professional eth- ics. Professional ethics, which are rules and values used in health care settings, govern the manner in which healthcare services are provided to the public. These rules and values tend to be disciplinespecific because of the varying duties of health professionals. As such, professional ethics often form the basis of registration requirements for health disciplines. Registration requirements are legislated, which means that the conduct of health professionals is governed by law. Moreover, the misconduct of health professionals is also legislated, and forms a basis of de-registration and rehabilitation.
Diesfeld and Godbold provide a detailed critical analysis of the complexities of $\mathrm{New}$ Zealand legislation and registration of health professionals, with specific reference to rehabilitation following disciplinary proceedings. These complexities relate to 19 health professions being governed by the same law and precedents, the varied make up of disciplinary panels and how each health profession may carry a different risk to the public, according to their respective roles and indiscretions. However, health professional legislation and registration is country or even province/state specific. This means that these issues, although relevant for New Zealand, may be less significant in other areas of the world.

In Australia, registration for health professionals is currently state-based, however, from 1 July 2010 national registration will be introduced, commencing with ten health professions (chiropractic, dental care, medicine, nursing and midwifery, optometry, osteopathy, pharmacy, physiotherapy, podiatry and psychology). Although the Health Practitioner Regulation National Law Act governs these professions, each profession will have discipline specific boards which will handle issues such as misconduct and rehabilitation. 
The principles which govern decisions regarding the appropriateness of rehabilitation, particularly in relation to physiotherapy, include:

- The risk to public safety

- The reasons and motivation behind actions and whether potential, actual, significant or longstanding harm to patient(s) and the profession was caused
- The health professional's medical state, demonstrated remorse and change in behaviour.

Importantly, serious misconduct where deliberate harm is caused to the patient is dealt differently to health professional incompetence and impairment.

Legislation and registration is a necessary part in protecting the safety of the public. Detailed attention of this aspect of pro- fessional practice should be provided to trainee health professionals during their university study. Complex patient-health professional situations and relationships are becoming more frequent and ethically challenging. Identification and discussion of these issues and the consequences of misconduct should be an essential component of health professional training.

\section{Cherie Wells}

Lecturer,

School of Biomedical

and Health Sciences,

University of Western Sydney

\section{Andrea Bialocerkowski}

Associate Professor,

School of Biomedical

and Health Sciences,

University of Western Sydney

a.bialocerkowski@uws.edu.au
I had to think of just how often I came across the issues raised in this article, in my former daily practice as a physiotherapist, and now as an educator. I strongly suspect my answer will be in common with many other qualified practitioners: rarely, and probably 'at a distance', rather than first-hand experience. The numbers being disciplined, relative to the numbers of registrants, are quite small, in New Zealand (NZ) or in the UK. Only those managing larger numbers would realistically have, or had to, consider a 'failing' registrant. This point will be returned to later.

Some comment first on the regulatory systems of both NZ and the UK. The system outlined in the paper is acknowledged as 'unusual', with the single pan-professional Health Practitioners Disciplinary Tribunal (HPDT). This is very different to the UK's nine regulatory bodies, further overseen by the Council for Healthcare Regulatory Excellence (CHRE).

The NZ approach could imply 'one size fits all' thinking; this does not come through from the literature, but one attraction this could have is a costs benefit to the regulators. The Tribunal was a response to other medico-legal legislation from the 70 s and 80 s, driving a need to 'fill in' regulatory 'holes' that became apparent. For example, the legislation that evolved the HPC (Health Professions Order 2001) from the Council for
Professions Supplementary to Medicine (CPSM) appears more motivated by restricting professional power in healthcare, if one reviews the policy documents from the period. The NZ approach can be lauded for a 'flattening' of the power dynamic between the healthcare professions represented. However, the question being posed by the examples given here is, although apparently treated equally, some registrants might be 'more equal' than others.

The two main examples in the text, $\mathrm{Dr} \mathrm{A}$ and $\mathrm{Mr} \mathrm{H}$, fit with the categories identified by Walshe (2009) and reflected in the areas regulatory panels are concerned with, mostly cases of 'misconduct'. From the professional, personal, moral and ethical view, these two registrants do not seem to be any different: they both have committed serious breaches of conduct contrary to their ethical and professional codes. The doctor was in a position of greater trust and authority: he could have seriously harmed his patients by failing to administer prescribed drugs, added to which he was already under a supervision order. The nurse committed the same 'offence' of potentially harming patient care, perhaps not quite as directly as the first case. The 'facts' therefore are very similar. That a rehabilitative approach was not offered to the nurse might prompt the suggestion of an 'extra' consideration being demonstrated here: the potential financial losses to the healthcare system.

The concept of rehabilitation was apparently built-in to the deliberations of the Tribunal from its inception. The HPC also seems to follow this ideal, although the most recent Fitness to Practice Report (HPC, 2009) first mentions 'to rehabilitate' on p47, and only in relation to an order of suspension in cases of competence or health. The findings of both panels are placed in the public domain, and it is clear that there is considerable debate and discretion exercised on individual cases. To see how decisions are reached, full transcripts of each hearing would seem to be the only way any meaningful comparison could be made, but this is obviously fraught with difficulties.

Studying the proceedings of regulatory bodies at undergraduate level might be one way of raising awareness of process and even of debate on what constitutes 'breaches'. Student work is 'tied' to regulatory body requirements, and students will be made aware of their codes of practise etc., at some point in their programme. This could be achieved through making professional healthcare students aware of how Student Fitness to Practice Panels operate, as their remit is based on the process for full registrants. There would be a forum for debate on not just the penalties, but how to manage 'failing' staff, in general terms, and what happens if they do 'fail'. This may help to reduce the increasing numbers referred to, for example, the HPC Conduct and Competence panels, where cases have risen from 15 'disposal decisions' in 2003-4 to 131 in 2007-8 (HPC, 2009).

The idea of rehabilitation for certain categories of professional misdemeanours should be fundamental to the process. It seems timely to begin thinking more about this area, with the increasing plethora of professional and statutory requirements that now 'hedge in' professional practise. Informing our neophyte practitioners of some of the deeper workings of their professional regulation would be a sensible starting point.

Health Professions Council (UK) (2009) Fitness to Practise Annual Report 2008, Health Professions Council, London

The Health Professions Order 2001 (SI 2002/254)

Walshe K (2009) Ch 7 'Regulating the Health Professions' in Healy J, Dugdale R (2009) Patient Safety First: Responsive Regulation in Healthcare. Allen \& Unwin Crows Nest, NSW

\section{John Bilham}

Senior Lecturer,

Canterbury Christchurch University,

Canterbury, UK

john.bilham@canterbury.ac.uk 
Copyright of International Journal of Therapy \& Rehabilitation is the property of Mark Allen Publishing Ltd and its content may not be copied or emailed to multiple sites or posted to a listserv without the copyright holder's express written permission. However, users may print, download, or email articles for individual use. 